\title{
What if I was harmful? Reflecting on the ethical tensions associated with teaching the dominant mathematics
}

\author{
Yasmine Abtahi ${ }^{1}$ (iD \\ Accepted: 5 October 2021 / Published online: 17 November 2021 \\ (c) The Author(s) 2021
}

\begin{abstract}
What are the effects of teaching the dominant mathematics on the wholeness and integrity of the cultural, social and linguistic resources of diverse communities? In this text, I seek to capture the risks associated with utilising non-Western resources in the teaching of the dominant mathematics in order to elucidate possible types of harms that conventional mathematics education could cause to various non-Western communities. In particular, I challenge various dominant theoretical views that endorse the employment of the social, cultural and linguistic (re)sources of others to teach and learn mathematics, without paying similar or even deeper ethical attention to the mutual and reciprocal effects of the taught and learnt mathematics. I propose an epistemology of interrelationships; I call attention to possible harms caused by utilising the social, cultural and linguistic (re)sources of some non-Western communities as part of the teaching and learning of dominant school mathematics on the same (re)sources of those communities.
\end{abstract}

Keywords Dominant mathematics $\cdot$ Harm $\cdot$ Ethical awareness $\cdot$ Epistemology of interrelationships

\section{The story of my teaching and the ethical tensions}

In the hope of building a more just society, Rorty (1999) explains that, instead of increasing our philosophical sophistication, we need to have "our attention called to the harm we have been doing without noticing that we are doing it" (p. 237). According to Rorty, hope is more than a state of mind or a goal in action. Hope is a narrative- "a story that serves as a promise or reason for expecting a better future" (p. 97). I therefore share a story in the hope of taking a step, albeit a small one, towards a more just future for mathematics teaching and learning. This is a reflective and theoretical paper about my experience during the summer of 2019, when I taught a 40-h mathematics pedagogy and content course to a group of Canadian indigenous teachers. I analyse and reflect on the tensions that I experienced in my mathematics pedagogy and content teaching and on the kind of mathematical knowledge that I was teaching.

Yasmine Abtahi

Yasmine.Abtahi@usn.no

1 University of South East Norway, Notodden, Norway 
In the field of critical mathematics education, it is highly endorsed to draw on the cultural, historical, linguistic and social (re)sources of other communities to teach and learn mathematics (see, for example, Ascher, 2018; D’Ambrosio, 2006; Naresh, 2015). My ethical tensions in my own teaching of mathematics education in the summer of 2019 arose precisely from this endorsement. I therefore ask myself the following question: how does the mathematics education community consider the ethical treatment of other communities to include the use of their (re)sources in these ways? This apparent contradiction is the ethical tension that I faced. My aim is to initiate the theoretical understanding of the ways in which and the extent to which the use of cultural, historical, linguistic and social (re) sources of other communities might cause harm to the integrity and wholeness of these communities' (re)sources, as we, the educators, with all good intentions, use these (re) sources to teach and learn mathematics.

In order to systematically reflect on the ethical tensions, I first draw on Varela's (1999) view of ethical know-how to explain why I decided to maintain vigilance towards my acts of teaching. I then provide examples to highlight three moments of awareness and to describe my spontaneous reactions in these three moments. In order to open a dialogue about the ethics of knowing how, I utilise the intertwined notions of "harm" and "hope" as articulated by Rorty (1999). Finally, in order to begin to theorise the possible areas of harm and hope, I draw on what I call "interrelationship epistemology." This epistemological view sees "knowledge" as constantly fluctuating in interactions and sees "becoming to know" as being entangled with ethical awareness of the web of interrelated actions and reactions, which in turn are rooted in cultures, histories and languages. Placing interrelationship epistemology at the heart of my analysis and reflection, I describe the ways in which my act of teaching could have caused harm to the integrity and wholeness of my students' cultures and to the histories of their community.

\section{Ethical awareness: remaining vigilant}

Before, during and after my summer of teaching in 2019, I remained keenly aware of the tensions that I was experiencing. There is a reason why I remained vigilant. Varela (1999) explains that a wise person is one who knows what is good and spontaneously does it. He explains that it is the immediacy of the perception and the action that we need to critically examine; this involves an ethical examination of the difference "between know-how and know-what" (p. 6). Of course, anyone can spontaneously react. However, to react spontaneously and wisely at the same time does not just happen. In his concern about what ethical know-how is and about how it is acquired, he presents "a plea for a re-enchantment of wisdom, understood as non-intentional action" (p. 75). He further explains that:

...this skilful approach to living is based on the pragmatics of transformation that demand nothing less than a moment-to-moment awareness of the virtual nature of our selves. In its full unfolding, it opens up openness as authentic caring. These are radical ideas and strong measures for the troubled times we have at hand, and the even more troubled ones we are likely to have. (p. 75)

I strove to remain conscious throughout my teaching and afterwards because I was concerned about acquiring ethical know-how in relation to my own act of (mathematics) teaching and learning. Acquiring such ethical know-how demanded nothing less than my moment-to-moment awareness of my actions and perceptions. So that as a result, either 
then or later, in troubled times, I would know what was good (wise) and I would be able to act spontaneously. To better understand what it means to be wise and what it means to take strong measures to respond to troubled times, I expanded Varela's (1999) vision of ethical know-how and dovetailed it with Rorty's (1999) ideas about hope-that is, hope for a better place that is rooted in having our attention called to any harm that we might be causing without our conscious awareness. Starting from the tension of "what harm could I have caused?", I now explain in detail my experiences, my ethical tensions, my reflections and, finally, my suggestions to the mathematics education community.

\subsection{Before my teaching}

To prepare myself for the teaching, I began to look closely at I-in-relations (see Abtahi, 2019a, b) for any suitable resources of any kind. In my previous work (Abtahi, 2019a, b), I drew on old Persian insights from Molavi Rumi (1253), who characterised living as a drafting compass. He explained that one leg of the compass is at its tip and is rooted in a particular time and place, while the other leg moves, drawing circles around the rooted leg. In other words, in the life of each person, there is a part that is strongly based on and is tied to their local root (comprised of cultures and collective and personal history) and a part that moves to connect with others-to feelings, places, cultures and people. In Abtahi (2019a, b), I built on this analogy to expand on the relationship between the rooted leg and the leg that moves to connect with others. I characterised this two-legged relationship as self-in-relations.

In making connections with others, I-in-relations to the mathematics education literature knew that I was surely not the first person to have been assigned to teach mathematics to a group of adults with a world view that is homogenously different from the Western world view, both culturally and epistemologically. Therefore, I sought conversations with colleagues who had attended the PME 43 conference, and I diligently consulted the works of relevant scholars, namely Tamsin Meaney, Tony Trinick, Lisa Lunny Borden and Jerry Lipka.

From my rooted leg, I drew upon two pools of resources. The first is a collection of observations and thoughts associated with my previous work. In these writings, I criticised the fact that the direction of undue attention to cultural diversities can siphon attention away from epistemological diversities (Abtahi, 2019a, b). The second is a collection of observations and reflections on myself over many years. Personally, I am neither a Western scholar nor an indigenous Canadian scholar. I am rooted in an ancient language and tradition, imbued with the meanings, sense-making and philosophies of Persia, which are fundamentally different from those associated with the language and tradition with which I engage on a daily basis as a member of the English-speaking academic community. Over years of studying and developing to become part of the English-language mathematics education community, I learnt a safe place from which I can write, speak, do and be in the standpoint of who I am-specifically in relation to my own roots. From this standpoint, I am dynamically accountable for my cultural location, my historical roots and my ways of knowing, all of which situate me in relation to others and to my cultural roots (Abtahi, 2019a). This accountability towards myself and my values creates constant (and uniquely enjoyable) tensions in the observations, decisions and stories that I share with other members of our research community.

I have benefited from the richness of the resources that have been created by maintaining continuous contact with my roots, by attending to and reflecting on the emergent 
tensions and by finding ways to navigate the world of research while remaining true to my own roots and values and to those of the mathematics education community. Alongside this awareness of self-in-relations, I was conscious of the fact that I was being paid to teach a government-mandated mathematics curriculum in which there was no genuine incorporation of any indigenous cultural and epistemological practices, let alone any mention whatsoever of the word "indigenous". I call this an "indifference curriculum". I am also conscious of the fact that, as an academic subject, mathematics is a gatekeeper (Espinosa, 2011) that holds many of the keys to the doors of material prosperity and life success. My awareness of self-in-relations has created a multi-dimensional ethical dilemma and has given rise to countless questions. Regardless of the extent to which I would strive to be culturally open, I could not avoid the reality that, as a result of the cultural misalignment of the government-mandated curriculum, I was going to teach a particular form of (mathematical) knowledge that, by default, holds systemic preferential power over other forms of knowledge. To what extent were my actions not just another exercise of (knowledge) imperialism? I continued to wonder about these issues while ethically hurting at the same time.

\subsection{During my teaching}

During my mathematics teaching, I tried to be as open and honest as possible with my students about who I am, about the place in which I am rooted and about the ways in which the use of my own cultural resources-resources and means upon which I draw when learning and teaching anything, including mathematics-helps me to respect and remain true to who I am in terms of my responsibilities towards my job and my community. I encouraged my students to do likewise, in any manner that made sense to them. I designated an hour of daily reading and reflection, reading papers by Fasheh (2012); Meaney et al. (2013); and other scholars. Every morning, in a ritual of circles, we shared the events of the previous day. We started by sharing events associated with our daily lives and then moved to our political, cultural and epistemological concerns while discussing in parallel the teaching and learning of mathematics. Before speaking in the morning circles, I reflected deeply on the events of the preceding days. Hence, I became even more aware of my own ethical tensions. To clarify, I now set out three examples of my moments of awareness and I describe my spontaneous reactions. I do this to establish a basis for conversations about the ethics of knowing how, harm and hope.

\subsubsection{Moment 1}

Moment 1 is my awareness of where I was standing within the web of interrelationships surrounding the content of the mathematics curriculum; the communities, cultures and histories in which my students are rooted; and my role as a teacher. One day I shared with my students my awareness of this indifference mathematics (as laid out in the Ontario mathematics curriculum) that I had brought with me to teach from. The students responded to my candour by sharing that they found the Ontario mathematics curriculum to be dishonest to the needs of their communities and to have been imposed on them. Various important questions were raised. For instance, what right do white teachers have, beyond their discredited claims to colonial rights, to teach us their 
"right way" of doing things? Or, how can white persons teach us if they do not know us? In a journal response to one of my students, I wrote the following:

I see your point about white teachers, and I entirely agree with it. I like to think that teaching and learning are two-way mutual activities. If we become humble enough to know that we shall learn, de-learn, and have our hearts open for new wisdom and knowledge, then the attitude of "I am the teacher" goes away: we all become "exchangers of knowledge(s)".

My spontaneous response, as quoted above, was offered with the utmost sincerity, at the time of addressing my student's concern. I truly felt that, in that class, the boundaries between teaching and learning had become quite fluid. However, upon further reflection, my response was not ethically satisfying to me. I was still bringing the mathematical knowledge(s) that the Ontario curriculum deem to be the "right" kinds of knowledge(s) to acquire; examples include the teaching of fractions and square numbers and the teaching of time using clocks.

\subsubsection{Moment 2}

Moment 2 is my epiphany of where I was standing within the web of interrelationships surrounding the dominant mathematical knowledge that I was teaching; my students' ways of knowing, seeing and imagining; and the preferential power that is held by the dominant (mathematical) knowledge. This second moment of awareness happened in the conversations that we had around various mathematical concepts. We spoke about how, for measurements, directions and time-telling, the ancestors of my students had relied on the respective movements of the sun, the moon, the stars and the planets; my students proceeded to express dissatisfaction with the curriculum of "the white school" since, in their opinion, it always focuses on artificial and contrived problems, with the solutions always being developed indoors and on paper. They explained how they had been taken off their aboriginal lands to be brought to the white schools, where they were labelled as incompetent. This dilemma certainly did not stop at that point. We moved forward to speak about the fact that, in order to survive in the white world, we need to understand and play by their mathematics (and their other systems).

At this moment, I had no spontaneous reaction to provide. I remained silent. I listened. For me, this conversation highlighted the power and the superiority embedded in the "white curriculum". The content of this indifference curriculum is something that my students needed to know, if they were to survive in the white people's system. This apparent requirement highlights the fact that, regardless of our preference and our will for thinking that we are participants in reciprocal and respectful cultural relationships among members of the Western, non-Western and indigenous worlds, this relationship is deeply contaminated with issues of power, authority and manipulation. Thus, I was left asking myself the following ethical question: how does the actual and the potential exercise of power (through people, institutions and/or the curriculum) continue to influence the ways in which students and their diverse communities define themselves in school systems, including in mathematics classrooms? 


\subsubsection{Moment 3}

Moment 3 occurred when I became aware of the web of interrelationships between my own teaching practices and the incorporation of the cultural and social resources of my students. My final epiphany involved the work of my class on the following mathematical task:

Karla uses 91 tiles to make six designs. Each design is a square and all are different sizes. How many tiles are used in each square? What is the length of the sides of each square?

I have used this task in more than 40 mathematics classes, and almost always the answers were the different sizes of squares as presented in Fig. 1. In my teaching experience, this task is not an introduction to the concept of squares. Rather, it is meant to be expanded upon so that one can talk about the idea of square numbers, such as $1^{2}, 2^{2}, 3^{2}, \ldots$, and about their relationships with the actual corresponding square figures.

In my summer of 2019 class, the designs turned out to be different. Some examples of my students' designs are set out below (Fig. 2).

For me, these designs triggered another set of ethical thoughts and reflections. Certainly they are visually attractive. Yes, the designs are all squares. But I asked myself how I should respond as a teacher. My students all knew about the squares. At this stage of my students' mathematical development, the Ontario mathematics curriculum dictates that I do not ask my students to make simple squares. They must instead be taught about square numbers. The time that we spent on making these designs could have been spent on a different task, related to square numbers. That was my job. That was the mandate of the curriculum. At this point, should I have left this activity as finished and have introduced square numbers in a different manner? Or should I have said that these results were not what I was expecting and have motivated the students to make the squares that I was expecting? As a teacher, the experience of being in such a situation is nothing new. In all of my classes, as a teacher, I regularly ask myself these kinds of questions, but then my spontaneous action is to move the task to the next level. In a different classroom, for example, I would have asked my students to make more squares, using another set of 91 tiles. But my spontaneous act in this instance, unique to this class, was to leave the task at the unique designs that had been created. Exiting the classroom, I asked myself why I had made this decision. Within the interrelationships among mathematical concepts, cultural designs and the mandate to cover the curriculum, why was this my spontaneous reaction? This example is only one of many

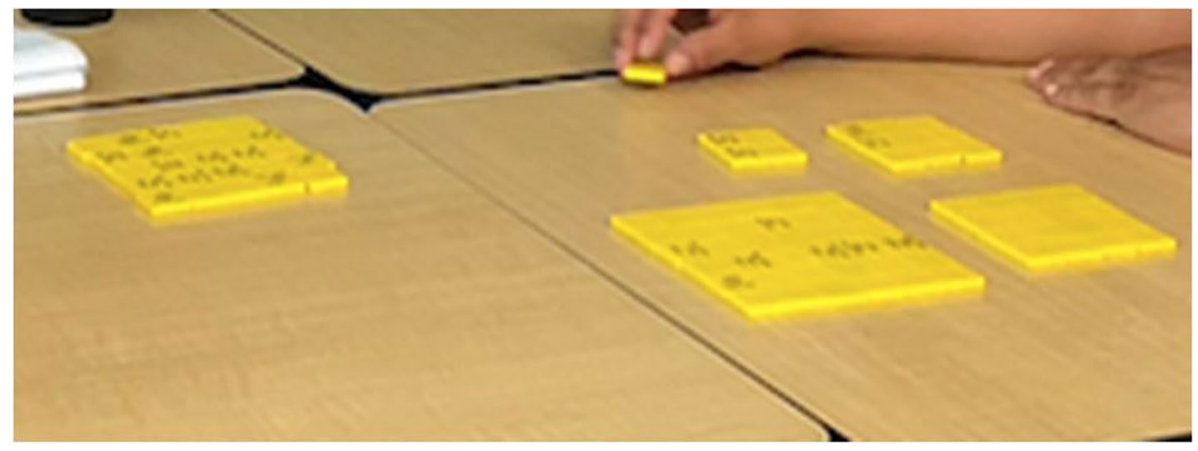

Fig. 1 Squares and squared numbers (and other elements). Picture taken by Yasmine 


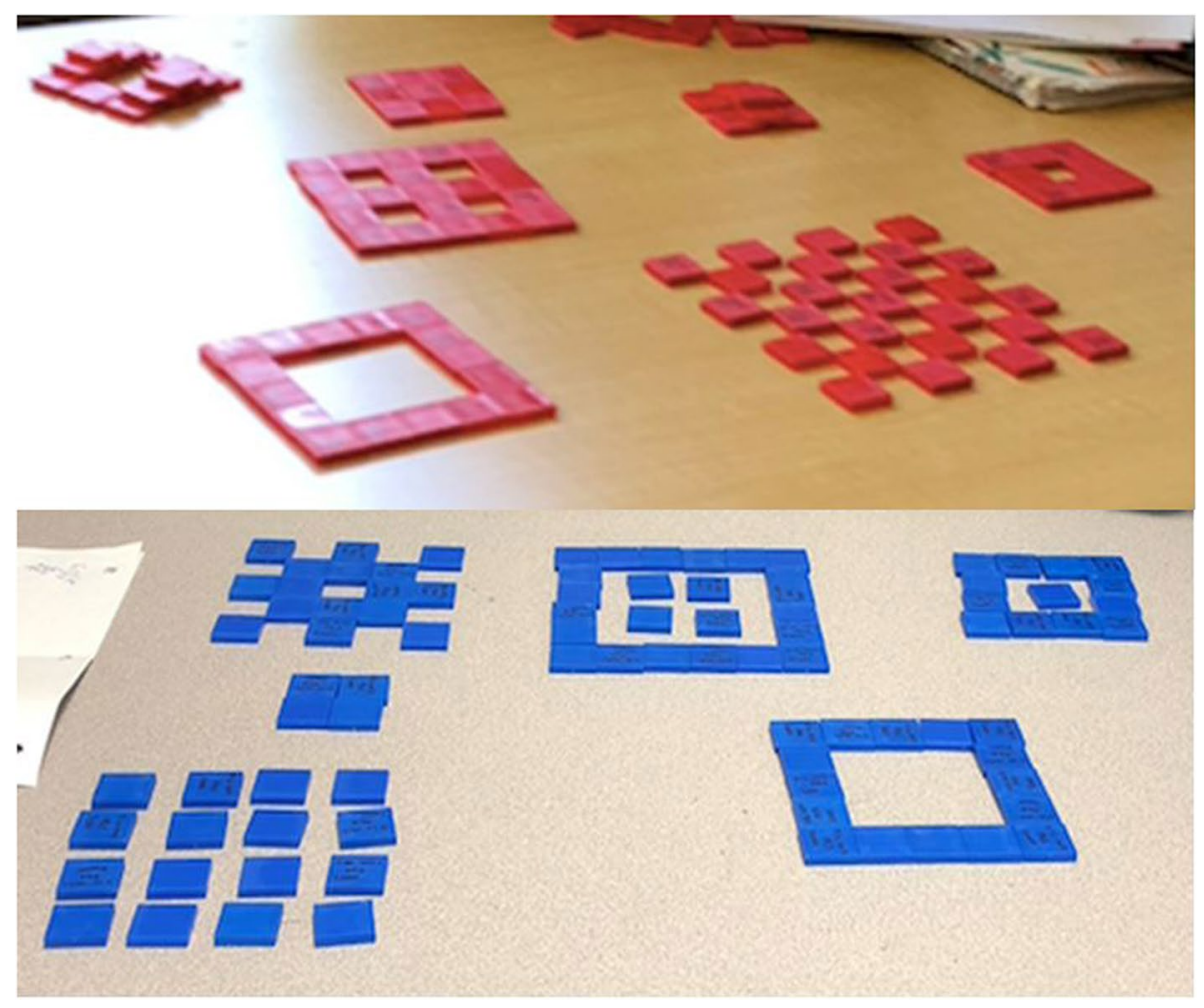

Fig. 2 Square designs (the designs in both pictures were replicated by me)

similar situations in which I was caught between the curriculum's mandated mathematical concept and the ethical imperative to genuinely and collaboratively incorporate the cultural resources of my students into their learning of the concept.

\subsection{After my teaching}

My teaching of this group of students is done. Yet, I am still left with my ethical dilemmas. In the hope of increasing my wisdom, I began further reflection by asking myself the following question: Did I cause harm, without my conscious awareness? This produced even more questions: What kinds of harm did I cause, through the type of mathematics that I taught and through the type of curriculum that I used? I did encourage my students to deploy their cultural resources in the process of learning. At the same time, I limited them to acquiring the kinds of knowledge that I had brought with me in my knapsack. In my knapsack, I carried fragmented and compartmentalised sets of knowledges, with little to no regard for any particular epistemologies, ways of knowing. These are the sets of knowledges that I characterise as mathematics, as laid out in the Ontario mathematics curriculum, for example.

In the hope of helping society move towards a more just and equitable future, I place the notion of "harm" in a different perspective. To do so, I systematically examine sets of epistemological assumptions, drawn from various ancient Persian schools of thought, one 
of which I conceptualise and interpret as comprising an epistemology of interrelationships. I use the "epistemology of interrelationships" to conceptualise "harm". Here, I have to note that my aim in conceptualising harm is to suggest new ways of generating hope for the more just teaching and learning of mathematics.

\section{An epistemology of interrelationships}

Critical mathematics education is a field that for decades has been challenging both conventional mathematics and its various approaches to teaching and learning. By way of example, Valero (2018) asks: "What is mathematics in relation to society, what does mathematics do as part of the school curriculum, and what are the potentials of mathematics education to produce or challenge inequalities in society and among students?" (p. 103). Similarly, Gutstein (2012) conducts an in-depth exploration into ways in which mathematics could be an instrument for promoting social emancipation; Pais (2013) challenges the purported universality of mathematics; and Skovsmose (2020) focuses on the marginalisation and even on the oppression perpetrated against non-Eurocentric mathematics. Building on the work of all these scholars and on the epistemological perspectives embedded in my own rooted heritage, I seek to challenge the types of experiences that are offered to students as they study and work on mathematics, especially by tapping into their cultural, social and linguistic resources. Part of the reason why I pursue this objective is to be able to understand the damage that could be inflicted on the cultural, social and linguistic (re) sources of these communities as a result of Western-trained educators picking into these (re)sources in an attempt to more effectively teach the dominant mathematics.

As I mention above in this paper, a safe place for me to think and reflect is the position of who I am in relation to my roots. I am rooted in 2,000-year-old written Persian philosophies of knowledge. For the purpose of this paper, I interpret one of these schools of thoughts to propose the epistemology of interrelationships.

Interrelationship epistemology understands knowledge to be a constantly moving interaction. This epistemology is not about an individual being in possession of intellectual ability or of knowledge or understanding about something. Instead, it is about knowing one's position in interpreting and engaging with the webs of other things (such as mathematical concepts) and with the multiplicities of one's experiences. In this epistemology, the goal is to capture the idea that knowledges are mutually dependent and are interrelated to ever-evolving life and cultural experiences. Knowledges are not fragmented. Let me provide an example. The sea is defined by the Cambridge Dictionary as a large area of salty water that is smaller than an ocean and is partly or completely surrounded by land. Knowing this definition is one way of knowing about the sea. Another way of knowing about the sea is knowing one's position within it—not as a knowing of mere information but as a knowing about how to safely relate to it by navigating it; by understanding its uses, benefits and dangers; and by thriving with it instead of simply surviving within it. This is a knowing about the sea's currents, wind, clouds, patterns of sea-bed sands and positions of the tide. At the same time, knowing the sea requires knowing about swimming, the memory of the muscles and the force of the currents and the waves on the skin. These are essential aspects of an ever-fluctuating knowing of a web of interconnected "things" that incorporates relationships in constant changes, exchanges and interactions. This is knowing the sea while swimming in it as opposed 
to knowing the sea as a definition in a dictionary. This is a knowing of self-in-relations as opposed to self-in-isolation. And this is the analogous and metaphorical basis for my Persian interinterrelations' epistemological frame of reference.

Within the epistemology of interrelationships lens, the act of learning is effectuated through consideration of the wholeness of the learner's lifelong process of accumulating experiences and interpretations. Hence, it follows that the act of teaching becomes highly ethical. This is especially the case in teaching across different cultures, when the teacher (an individual such as myself) or the subject that she/he is teaching (such as mathematics) does not have an understanding of the fluctuating webs of interconnected things that the learners are carrying in their positions as selves-in-relations. The act of teaching is ethical because of the harm that could be caused by the lack of attention to epistemology of interrelationships, regardless of the teacher's intention.

This paper began with an invitation to call our attention to the harm that we have been causing without noticing that we have been causing it. Expanding on this idea, Rorty says that "It is best to think of moral progress as a matter of increasing sensitivity, increasing responsiveness to the needs of a larger and larger variety of people and things" (p. 237). I follow the ethical philosophy of Saadi (1285), which takes as a starting point the following statement:

All humans are inherent parts (or, more literally, limbs) of one body and are created from the same essence (or, more literally, gem). When the calamity of time and space hurts one, others shall be disturbed. If you are indifferent about and have not empathy for the sufferings of others, you are unworthy to be called a human.

In this (translated) statement, the increase in sensitivity and responsiveness is encapsulated in having "empathy"that is, an other-oriented and imaginative attempts to experience events as another human has experienced them. In his

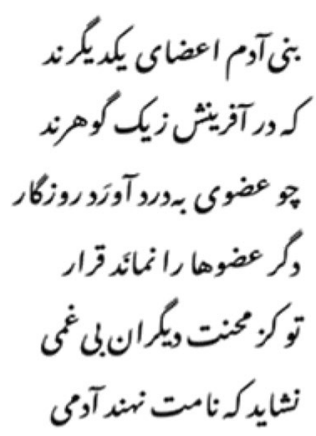
Book of Golestan, Saadi (1285) highlights the necessity of having empathy for conducting oneself in an ethical manner; unless we can imagine the world from the point of view of others-people and things whose experiences, contexts and ways of living are very different from our own-we are likely to act (albeit unintentionally) in ways that are detrimental to these others' individual and/or communal wellbeing. As custodians of the well-being of our learners-in-relations, empathy gives us as teachers a sense of what it is like to be someone else and a sense of other possible ways of knowing in the world. Subsequent reflection on our own experiences of empathy in turn become another area of ethical significance because they help us to recognise whether and in what ways our actions might have caused unwanted harm through failures to notice and acknowledge other ways of knowing. The recognition of any possibility of causing harm has another level of ethical significance because it creates a sense of responsibility, a duty to care about the well-being of others. Thus, empathy, which engages the capacity to imagine, becomes a necessary condition for ethical thinking and ethical action. According to this perspective, understanding the discipline of ethics extends beyond identifying the distinctions between and understanding the nature of "right" and "wrong" and "good" and "bad". It encompasses such matters as "responsibility", "accountability" and "duty"-not one's duty as a "good citizen", but instead one's duty as a person who genuinely cares about selves and selves-in-relations. 
Right-pointing arrow: The benefits of

this relationship seem to be endorsed.

Social, cultural and linguistic (re)sources of other(s) to teach and learn mathematics

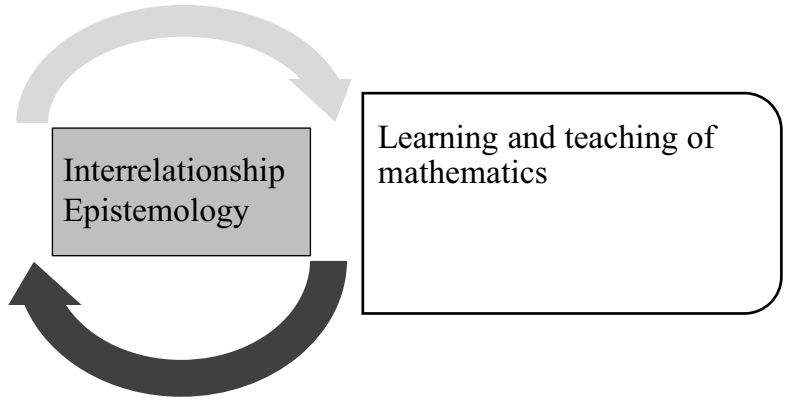

Left-pointing arrow: Is this relation harmful? If so, how and why?

Fig. 3 Portrayal of my ethical concern

Hence, for a teacher like me, a moment-to-moment awareness of my spontaneous wise acts is (and must be) entangled with my ethical awareness of the reciprocal web that is interrelated, interdependent and interconnected with my students' life experiencesincluding those life experiences that are rooted in and have sprouted from their culture, history and languages.

Now, as an application of epistemology of interrelationships, I challenge the use of the social, cultural and linguistic (re)sources of others to teach and learn mathematics, without paying similar or even deeper ethical attention to the mutual and reciprocal effects of the taught and learnt mathematics on those social, cultural and linguistic (re)sources. For me, this is a matter of ethical concern because I am seeking to determine whether and in what ways I may have caused harm in the process of teaching the Ontario mathematics curriculum to Canadian indigenous students. The following figure portrays my ethical concern:

Figure 3 represents the idea that it is important to incorporate the social, cultural and linguistic (re)sources of others-individuals whose cultural and linguistic (re)sources are unfamiliar to us-into the teaching and learning of mathematics. Yet, at the same time, it issues an invitation to think about the ways in which the learnt mathematics feeds back to affect the social, cultural and linguistic (re)sources of others and about the extent to which this form of mathematics has the ethical qualities necessary for preserving the wholeness of those (re)sources. In other words, my invitation is to be vigilant and careful to ascertain whether and in what ways utilising the resources of culturally non-dominant communities in the process of teaching "culturally dominant" mathematics might cause harm to those communities and to their cultural resources.

\subsection{The right-pointing arrow: including (re)sources of other(s) in the teaching and learning of mathematics}

In order to teach mathematics, with the greatest possible breadth and commitment to social justice, we tap into a range of cultural, historical and linguistic resources. Among others, the two theoretical perspectives known as "ethnomathematics" (D'Ambrosio, 2006) and "funds of knowledge" (González et al., 2009) are greatly appreciated in the field of critical 
mathematics education. These two perspectives disrupt the deficit models of teaching and learning and instead offer alternatives characterised by respect for and understanding of other cultures and ways of living. Ethnomathematics and funds of knowledge each offer a positive and realistic perspective on the cultural and cognitive resources possessed by members of diverse communities combined with an appreciation of their potential value in the teaching and learning of mathematics. Baker (2005) views funds of knowledge in relation to students as encompassing "knowledge, experiences, histories, identities and images of themselves; attitudes, dispositions, desires, values, beliefs, and social and cultural relations" as well as "relationships with learning, teachers and mathematics itself" (p. 16). Ubiratan D'Ambrosio (2006) defines ethnomathematics as "a research program in the history and philosophy of mathematics, with obvious pedagogic implications" (p. 27). He identifies the dimensions involved in ethnomathematical research as being historical, cognitive, epistemological, political and educational:

...in order to better teach mathematics and in order for the students to better learn it, we thought using knowledges, politics, experiences, histories, epistemologies, identities and images of students (and those of the teachers) as well as their dispositions, desires, values, beliefs to be included into the structure of our mathematics classrooms (D'Ambrosio, 2006, p. 27).

D'Ambrosio's suggestion includes, for example, comparing the Canadian indigenous tradition of beading with the dominant mathematical idea of patterning, the African cultural act of making wedding pottery with geometry and the highly sophisticated act of canoe-making with measurement.

The body of mathematics education research includes countless studies that have invited the cultures and perspectives of diverse communities into innovative approaches to the teaching and learning of mathematics. Naresh (2015) uses the example of Kolam drawings, which comprise decorative designs created by women in south India using rice flour and decorated with flowers. Naresh (2015), in referring to Ascher (2018), explains that the ritual of Kolam drawing can be viewed as a sociocultural activity that offers great potential for teaching and learning mathematics. While interacting with Kolams, Naresh's students identified geometry (specifically polygons and transformations), algebra (specifically patterns and sequences) and combinatorics and discrete mathematics as mathematical ideas that can possibly be taught using these south Indian designs. This example endorses the utilisation of the cultural and historical resources of others to teach mathematics.

Languages, linguistic diversities and multiplicities of discourses comprise another socially provided supply of resources that is being increasingly utilised in mathematics classrooms to teach mathematics in a socially just and fair manner. Over the last few decades, the role played by language has become an active focus of investigation in mathematics education research (as noted by Radford and Barwell (2016) in their analysis of 10 years of such research as set out in various PME proceedings). Building on the fact that, in the critical field of mathematics education, the use of ideas and issues related to languages is no longer emergent and therefore is at the stage of requiring theoretical conceptualisation, Planas (2018), expanding Ruiz's (1984) orientations on language to learners, proposes a reconceptualisation of the learners' social languages and systems of languages "as discursive dialectical sites of potential/actual and shared/non-shared meaning production" (p. 215) in which language is characterised as a "resource". In regard to this suggestion, the premise of Planas's (2018) socio-political ideology (an ideology to which I largely subscribe) is that the languages used in mathematics learning cannot and should not be separated from other languages in order to privilege some languages within the mathematics 
learning processes. Along similar lines to Planas, Barwell (2018) reviews and critiques the idea of "language as a resource" in explaining some of the limitations associated with the materialisation of language. Drawing on Bakhtin's theory, he proposes "language as a 'source' of meaning" (Barwell, 2018, p. 155). Emphasising the ideas that language is agentive, meaning is relational, and language is diverse and stratified, he further explains that:

Students and teachers work with repertoires of practices relating to discourses, voices and languages, to do mathematics: they language mathematics, rather than use mathematical language. Mathematical meaning-making happens through the dialogic relations between the diverse discourses, voices and languages that arise, in written and spoken classroom interaction (Barwell, 2018, p. 162).

Thus, a common element running through Planas's and Barwell's respective conceptualisations of languages as (re)sources is the goal of teaching and learning mathematics in more equitable, inclusive and just ways by utilising the cultural, historical and linguistic resources of others.

I now articulate my own contribution, which is an invitation to be vigilant and careful about our own acts of teaching and learning mathematics, especially when using (re) sources of others whose ways of knowing are not necessarily Western-oriented.

\subsection{The left-pointing arrow: what does mathematics give to the (re)sources of non-Western communities?}

Does the teaching and learning of the dominant mathematics provide a sufficient basis for drawing upon the cultural, linguistic and relational resources of communities whose ways of knowing and seeing are fundamentally different from those that we endorse as mathematics educators? I hope so. To further elaborate my question, I ask a number of interrelated questions. What forms of social, cultural and economic capital are afforded by this mathematics that we reproduce, in identical or expanded forms, using the resources available within various communities? With respect to the epistemology of interrelationships perspective, what kinds of elements are offered by the mathematics that we teach that induce us to use whatever (re)sources we have available for teaching it? These include the most intimate resources identified by Baker (2005), including experiences, histories, identities and groups' and individuals' images of themselves, as well as attitudes, dispositions, desires, values, beliefs and social and cultural relations. My deeper and more philosophical question is as follows: What kinds of harm might be caused to these communities if, after having selected particular community resources for the purpose of teaching mathematics, we unwittingly assign to them a value of "goodness" or "badness" that has nothing to do with their intrinsic worth within that community? An example of the ethical tension that this question poses for me is my summer of 2019 teaching experience. Throughout this experience, I was keenly aware of the fact that, even though I was trying to use the cultures, languages and histories of my students, I was still limiting them to acquiring the kinds of mathematical knowledge that I had brought with me.

The most fundamental issue that I would like to raise here is that the selected cultural and linguistic resources that are deployed to more effectively teach and learn mathematics are not inherently superior to any other resources within the communities in question. In the hierarchical and value-laden form of dominant mathematics, these resources are seemingly "worth more" because they are valued by those in positions of power-individuals 
who generally have a strong knowledge of specific kinds of mathematics. We pick particular cultural artefacts, linguistic forms and historical facts from various cultures and communities insofar as they apply to the kinds of mathematics that we teach and not as elements that are independently worthy of selection. This targeted selection gives a particular body of mathematical knowledge a privileged position and the appearance of greater legitimacy from the perspective of the dominant discourse around the kinds of actions, beings and doings that are considered to fall within the scope of formal (i.e., school) mathematics. This is a powerful and dangerous scenario.

I will clarify this position with an example. The cultural act of knitting in some Sami communities often is selected as a cultural resource in the teaching of mathematics. This is because this activity seems familiar. In the dominant ways of thinking about mathematics, knitting resembles patterns. Yet the act of knitting — as a collective story of who one is and where one is coming from-may or may not be worth more than any other act in the daily lives of members of that community. It is not the cultural act per se, but instead the importance of learning patterning that leads to the selective picking of the act of knitting. So let me ask my question again: To what extent is the inclusion of the Sami cultural act of knitting in the teaching of the dominant mathematics of patterning an act that is harmful to the historical and cultural well-being of this community? Recursively, what does the idea of "knitting is patterning" do to the wholeness and integrity of the Sami community? I argue that, unless I can empathically imagine the world from the point of view of a person in this community whose knowing about "knitting", both in experience and in context, is very different from my own experience with "patterns", my act of connecting knitting and patterning is deleterious to his/her welfare and hence could be harmful. In the hope of moving towards a more just teaching and learning of mathematics, this is yet another example of why we, as teachers and researchers, must endeavour to be more vigilant about our own actions, to notice the harm that could be caused, without being noticed.

\section{A return to self-in-relations}

Endorsing a more just and fair approach to mathematics education, for decades, scholars have highlighted the many types of interaction that can occur between different forms of domination and non-dominant parties, including the domination of races, cultures and/or mathematical traditions themselves. Returning to the notion of self-in-relations, I now turn to the tensions that I raise in this paper, locating them within a sample of a broader network of pre-existing tensions in mathematics education research. I position myself within these relationships in order to underline how the epistemology of interrelationships could shed light on these tensions from a different angle. I-in relation to the research that I have conducted in the field of mathematics education-have noticed ethical tensions that resemble those raised in this paper. To exemplify, Valero et al. (2012), in a research project focused on Latin American indigenous students in Colombia, explored how mathematics educators can contribute to students' opportunities for living in and with dignity. Raising an ethical tension, Valero et al. (2012) ask:

How we could possibly engage as teachers and as researchers in going beyond our understanding of that situation, and how we could engage students recovering one thing: their dignity of being the social, historical human beings that they were, with a possibility of imagining a future (p. 6). 
Based on their research activities, they suggest a mathematics curriculum organised not around central mathematical ideas or competencies, but instead around traditional mathematical concepts. Martin (2013), in analysing "what kind of project" mathematics education is, asks another ethical question: "How do race and racism structure the very nature of the mathematics education enterprise?" (p. 322). Quoting Ray Rist (1978), he states that assimilation is a "means of socialising non-white students to act, speak and believe very much like white students". It leaves dominant values intact, does no damage to notions of white superiority and helps to gain the support of those whites who view it as a means of helping "non-white peoples to become fully human by instilling in them 'white' ways of thinking and feeling" (p. 327). Raising our field's level of ethical awareness, Martin asks us, as researchers, the following question: "How do we continue to make sense of the highly racialized nature of mathematics education, both as a knowledge-producing domain and as an activity experienced by teachers and students on a daily basis?" (p. 328). Trinick et al. (2015) underline the cultural clash that occurs when indigenous students' cultures intersect with the culture that surrounds the mathematics taught in classrooms. In another paper, Meaney and Evans (2013) claim that mathematics education "must take seriously its responsibility to support Indigenous students to gain school mathematics and also to help maintain the use of traditional mathematical ideas." Shaking the core of our ethical comfort zone, they warn us that "If this does not occur, mathematics educators will contribute, intentionally or unintentionally, to the loss of Indigenous knowledge that present and future generations of Indigenous people will hold them responsible for" (p. 481). Civil and Planas (2012) in reflecting on mathematics education and language diversity directly ask "Whose language" is it that is being valorised. Finally, I refer to Pais (2011) as he claims that the claim of giving voice to the oppressed (poor students, ethnic students, minorities and so on) endorses the spirit of capitalism. It might allow people to ease their consciousness but assures "that no fundamental change in schools or in the economical organization of society occurs" (p. 227).

I acknowledge that the concept of ethics is not the main focus of any of the research studies mentioned above. Yet I perceive an underlying element of hope that runs through the messages. In mathematics education community, these studies convey ethical messages to me, within the web of the interconnected "things" with which I am-in-relation. Ethical questions-such as "whose mathematics?" (Valero et al., 2012), "whose race?" (Martin, 2013), "whose culture?" (Trinick et al., 2015), "whose language” Civil \& Planas (2012) and "whose voice?" (Pais, 2011)—have become bases for my ever-fluctuating knowings that have led me to ask and conceptualise the question of "what harm?". Within the interrelations epistemology, I systematically analysed the question of "what harm?" to conclude that the use of the resources of culturally non-dominant communities in order to teach "culturally dominant" mathematics causes harm to these communities and to their cultural resources. Drawing on the ethical considerations that underlie the epistemology of interrelationships, I have submitted an invitation to hope by developing even more sensitivity to the pains and sufferings of others and an invitation to a wider and wider empathy.

\section{Further discussions}

In this paper, I capture moments from my teaching experience with students from various Canadian indigenous communities, with the objective of understanding whether and in what ways I might have caused harm by teaching the conventional mathematics as 
mandated in the Ontario curriculum, as I, with all good intentions, drew on my own cultural, historical, linguistic and social resources and on those of my students. To conceptualise my experiences and the possible harms, I provided examples of moments of ethical conflict as well as my spontaneous actions in relation to those moments. I did this in order to be able to act wisely at troubled times (Varela, 1999).

I introduce the concept of epistemology of interrelationships, which sees "knowing" as being embedded in a reciprocal web that is interrelated, interdependent and interconnected with one's life experiences-including those experiences that are rooted in and that sprout from one's culture and history. If learning is conceptualised as an ever-evolving web of events and thoughts that is entangled with one's roots as well as with one's location within this constantly changing network, it follows that teaching becomes a highly ethical act. Teaching becomes ethically charged because it becomes accountable for the mutual constitution of webs of entangled relationships between the teacher, the learners and their roots, including the web of epistemological, political and historical experiences in which the learners' knowing develops and takes on important parts of their culture. I use epistemology of interrelationships as an ethical lens through which to examine the recursiveness of the relationship between the use of the cultural, historical, linguistic and social resources of non-Western communities in the teaching and learning of mathematics on the one hand and the effects of the acquired mathematical knowledge on the cultural, historical and linguistic resources of those communities on the other hand. I do this in the hope to be more wise in my own teaching of mathematics by ascertaining whether I was harmful while teaching the dominant mathematics to a class of Canadian indigenous teachers during the summer of 2019.

With the least of such intentions, I determine that I could have been ignorant at the least and harmful at the most. Conscious of the importance of including cultural, social and linguistic resources, I attempted to incorporate my own culture and ways of knowing and those of my students into the teaching and learning. I could have been ignorant because I did not pay attention to the fact that the cultural resources that I selected may not have greater value to members of the community in question than many of the other resources within that community. This kind of inclusion of cultural and other resources takes no account of the community's distinctive value systems, which might have nothing to do with mathematics (at least as represented in a curriculum). Therefore, such an approach, regardless of how well intentioned it might be, risks trivialising the cultural resources of the community. It invests these resources with mathematical meanings from the "outside"-meanings that may not have any connection with those invested in them by members of that community. I could have been harmful, because I did not pay attention to whether and in what ways the type of (mathematical) knowledge that I had brought with me, as presented in the culturally misaligned Ontario mathematics curriculum, affected the cultural, linguistic and social resources of my students and, in particular, the resources and the wholeness of the integrated practices that make them the selves that they are-in-relations.

\section{Concluding remarks and recommendations}

I shall begin by stating that I endorse utilising practices and resources of all communities for a more fair and inclusive teaching and learning of mathematics classrooms. I practise it. Theoretical perspectives within critical mathematics education, such as ethnomathematics, 
funds of knowledge and countless studies that branched from the roots of these theoretical perspectives, have created the foundations for inclusivity and fairness in mathematics classrooms that could not have been imagined otherwise. In building on these theories, I initiated an ethical theoretical understanding to explore how the use of cultural, historical, linguistic and social (re)sources of other communities, in teaching and learning of dominant school mathematics might cause harm to the integrity and wholeness of these communities' (re)sources.

My point is the ethical dimension. The systematic ethical investigation of utilising the cultural, historical and linguistic resources of non-Western communities to teach the dominant mathematics has rarely played a central role in our analyses, has rarely been theorised for conceptual clarity and has rarely been theorised in relation to the kinds of suffering that could be imposed on the cultural, historical and linguistic integrity of the non-Western communities in question. While utilising resources and practices of non-Western communities, in teaching and learning of school mathematics, my plea is an invitation to be slow, cautious and ethically careful. This care and attention opens up agendas both in research and in practice, a dimension to explicitly and systematically plan for ethical considerations. To oversee and speculate the (possible) harm that is associated with the teaching and the learning of school mathematics and to recognise the harm that we might be doing, without noticing that we are doing it.

My plea is also a request of "nothing less than a moment-to-moment awareness" (Varela, p. 75) of ourselves-in-relation to the possible harm that mathematics and its learning and teaching could cause for members of different communities. Ethical considerations and the empathy that is associated with the epistemology of interrelationships are to create a base for what Varela says to be "strong measures for the troubled times we have at hand, and the even more troubled ones we are likely to have" (p. 75). Expansion of such ethical awareness in recognition of the harm is not only for Canadian indigenous colleagues, but also for non-Western others. "Being/doing things unintentionally" or "being/ doing things unconsciously" is not enough because, ultimately, causing harm is causing harm. I conclude by an invitation to hope for the highest appreciation of selves-in-relations, where more and more students and teachers feel that both their rooted and moving legs are appreciated.

Acknowledgements I am thankful to Professor Merrilyn Goos for having conversations with me, for listening to me and for very delicately guiding me.

I am thankful to Professor Nuria Planas for her care and thoughtful comments and reviews.

Funding Open access funding provided by University Of South-Eastern Norway.

\section{Declarations}

The manuscript has not been submitted elsewhere. The work has not been published elsewhere. There were no human participants in the research. The research is not funded by anyone. There are no conflicts of interest.

Open Access This article is licensed under a Creative Commons Attribution 4.0 International License, which permits use, sharing, adaptation, distribution and reproduction in any medium or format, as long as you give appropriate credit to the original author(s) and the source, provide a link to the Creative Commons licence, and indicate if changes were made. The images or other third party material in this article are included in the article's Creative Commons licence, unless indicated otherwise in a credit line to the material. If material is not included in the article's Creative Commons licence and your intended use is not permitted by statutory regulation or exceeds the permitted use, you will need to obtain permission directly from the copyright holder. To view a copy of this licence, visit http://creativecommons.org/licenses/by/4.0/. 


\section{References}

Abtahi, Y. (2019a). Epistemological dialogue: Other ways of knowing and our blind spots. Journal of Mathematics and Culture, 13(1), 1-19.

Abtahi, Y. (2019). More than cultural awareness: Awareness of self-in-relation. The Philosophy of Mathematics Education Journal. 35. Open access.

Ascher, M. (2018). Mathematics elsewhere. Princeton University Press.

Baker, D. (2005). Numeracy and 'funds of knowledge'. Reflect, 3, 16-17.

Barwell, R. (2018). From language as a resource to sources of meaning in multilingual mathematics classrooms. The Journal of Mathematical Behavior, 50, 155-168.

Civil, M., \& Planas, N. (2012). Whose language is it?: Reflections on mathematics education and language diversity from two contexts. In Alternative forms of knowing (in) mathematics (pp. 71-89). Brill Sense.

D'Ambrosio, U. (2006). Why ethnomathematics? In Ethnomathematics (pp. 5-15). Brill Sense.

Espinosa, L. (2011). Pipelines and pathways: Women of color in undergraduate STEM majors and the college experiences that contribute to persistence. Harvard Educational Review, 81(2), 209-241.

Fasheh, M. J. (2012). The role of mathematics in the destruction of communities, and what we can do to reverse this process, including using mathematics. Opening the cage (pp. 93-105). Sense Publishers.

González, N., Moll, L. C., \& Amanti, C. (2009). Funds of knowledge: Theorizing practices in households, communities, and classrooms. Routledge.

Gutstein, R. (2012). Mathematics as a weapon in the struggle. In O. Skovsmose \& B. Greer (Eds.), Opening the cage: Critique and politics of mathematics education. Sense Publishers.

Martin, D. B. (2013). Race, racial projects, and mathematics education. Journal for Research in Mathematics Education, 44(1), 316-333.

Meaney, T., \& Evans, D. (2013). What is the responsibility of mathematics education to the Indigenous students that it serves? Educational Studies in Mathematics, 82(3), 481-496.

Meaney, T., Trinick, T., \& Fairhall, U. (2013). One size does not fit all: Achieving equity in Māori mathematics classrooms. Journal for Research in Mathematics Education, 44(1), 235-263.

Molavi Rumi (1253 CE). Spiritual Couplets.

Naresh, N. (2015). The role of a critical ethnomathematics curriculum in transforming and empowering learners. Revista Latinoamericana De Etnomatemática, 8(2), 450-471.

Pais, A. (2011). Criticisms and contradictions of ethnomathematics. Educational Studies in Mathematics, 76(2), 209-230.

Pais, A. (2013). Ethnomathematics and the limits of culture. For the Learning of Mathematics, 33(3), 2-6.

Planas, N. (2018). Language as resource: A key notion for understanding the complexity of mathematics learning. Educational Studies in Mathematics, 98(3), 215-229.

Radford, L., \& Barwell, R. (2016). Language in mathematics education research. In The second handbook of research on the psychology of mathematics education (pp. 275-313). Brill Sense.

Rist, R. C. (1978). Sorting Out the Issues: The Current Status of School Desegregation. Civil Rights Digest.

Rorty, R. (1999). Philosophy and social hope. Penguin Books.

Ruiz, R. (1984). Orientations in language planning. NABE journal, 8(2), 15-34.

Trinick, T., Meaney, T., \& Fairhall, U. (2015). Finding the way: Cultural revival through mathematics education. In Exploring different theoretical frontiers - A symposium In Mathematics Education and Society Conference, 224-230.

Saadi (1285 CE). Golestān.

Skovsmose, O. (2020). What could critical mathematics education mean for different groups of students? Rethinking Critical Pedagogy, 1(1), 1-16.

Valero, P. (2018). Human capitals: School mathematics and the making of homuso-economicus. Journal of Urban Mathematics Education, 11(1 \& 2), 103-117.

Valero, P., García, G., Camelo, F., Mancera, G., \& Romero, J. (2012). Mathematics education and the dignity of being. Pythagoras, 33(2), 1-9.

Varela, F. J. (1999). Ethical know-how: Action, wisdom, and cognition. Stanford University Press.

Publisher's note Springer Nature remains neutral with regard to jurisdictional claims in published maps and institutional affiliations. 